\title{
Taxonomical study into two new species of Philometra (Nematoda: Philometridae) previously identified as Philometra lateolabracis (Yamaguti, 1935)
}

\author{
Karl Marx A. Quiazon ${ }^{1,2}$, Tomoyoshi Yoshinaga ${ }^{1}$ and Kazuo Ogawa ${ }^{1}$ \\ ${ }^{1}$ Department of Aquatic Biosciences, Graduate School of Agricultural and Life Sciences, The University of Tokyo, Yayoi 1-1-1, \\ Bunkyo-ku, Tokyo 113-8657, Japan; \\ ${ }^{2}$ Freshwater Aquaculture Center and College of Fisheries, Central Luzon State University, Science City of Muñoz, Nueva Ecija, \\ Philippines 3120
}

Keywords: Philometra lateolabracis, Philometra madai, Philometra isaki, Nematoda, philometrids, ITS2 rDNA, morphology, molecular study

\begin{abstract}
Males of the nematode Philometra lateolabracis (Yamaguti, 1935), the type species of the genus Philometra Costa, 1845, were discovered for the first time in gonads of its type host, the Japanese seaperch, Lateolabrax japonicus (Cuvier). Morphological comparisons carried out between the collected male and female P. lateolabracis with the male and female philometrid nematodes previously reported as $P$. lateolabracis infecting chicken grunt, Parapristipoma trilineatum (Thunberg), and red sea bream, Pagrus major (Temminck et Schlegel), revealed that the latter represent two new species, Philometra isaki sp. n. and Philometra madai sp. n., respectively. Molecular comparison of ITS2 rDNA between P. lateolabracis and P. madai supported the morphological conclusion that the two nematodes obtained from different fish species should be assigned to different species.
\end{abstract}

Nematodes of the superfamily Dracunculoidea Stiles, 1907 represent a widely distributed and very diverse group of species which infect different freshwater, brackish-water, and marine fishes. According to Moravec (2004), taxonomy and classification of dracunculoids require a fundamental re-evaluation based on detailed studies of individual species, including the use of new methods such as scanning electron microscopy (SEM) and molecular analyses. Most species of these large histozoic parasites are poorly known, both biologically and taxonomically. Especially males have not been discovered in most dracunculoid species.

Nematodes belonging to the family Philometridae Baylis et Daubney, 1926 are frequently found in various organs, tissues and body cavities of a wide variety of fishes. Most previously reported philometrids were conventionally identified to species level using only light microscopy (LM). Currently, SEM has been performed on a number of morphological structures that cannot be clearly determined by LM. Moreover, identification of philometrid species has often been done solely using females, as males (TL $<5 \mathrm{~mm}$ ) are generally much smaller than females (TL usually $>100 \mathrm{~mm}$ ) and cannot be collected easily. Most philometrids remain poorly known, and their identification is usually very difficult and problematic because of difficulties associated with their morphological and biological peculiarities (Moravec et al. 2003, Moravec and Genc 2004).

Philometra lateolabracis (Yamaguti, 1935) has been repeatedly reported in the gonads not only from its type host, the Japanese seaperch Lateolabrax japonicus $(\mathrm{Cu}-$ vier) (Percichthyidae), but also in members of other perciform families (Ariidae, Carangidae, Centropomidae, Glaucosomatidae, Haemulidae, Hemiramphidae, Lutjanidae, Mullidae, Muraenesocidae, Paralichthyidae, Polynemidae, Pomadasyidae, Psettodidae, Sciaenidae, Serranidae, Sparidae) from tropical and subtropical regions of the Mediterranean, Pacific, South Pacific, Indian and Atlantic Oceans. Reported hosts of P. lateolabracis are as follows: chicken grunt, Parapristipoma trilineatum (Thunberg); Hong Kong grouper, Epinephelus akaara (Temminck et Schlegel); dusky grouper, Epinephelus marginatus (Lowe); speckled blue grouper, Epinephelus cyanopodus (Richardson); blacktip grouper, Epinephelus fasciatus (Forsskål); grunt, Haemulon plumieri (Lacépède); red sea bream, Pagrus major (Temminck et Schlegel); snapper, Pagrus auratus (Forster); westralian jewfish, Glaucosoma hebraicum Richardson; greater amberjack, Seriola dumerili (Risso); mottled grouper, Mycteroperca rubra (Bloch); daggertooth pike conger, Muraenesox cinereus (Forsskål); giant sea catfish, Arius thalassinus (Rüppell); long billed halfbeak, Rhynchorhamphus georgii (Valenciennes); barramundi, Lates calcarifer (Bloch); lane snapper, Lutjanus synagris (Linnaeus); Indian goatfish, Parupeneus indicus (Shaw); fourfinger threadfin, Eleutheronema tetradactylum (Shaw); Belanger's croaker, Johnius belangerii (Cuvier); coitor croaker, Johnius coitor (Hamilton); sin croaker, Johnius dussumieri (Cuvier); blotched croaker, Nibea maculata (Bloch et Schneider); tiger-toothed croaker, Otolithes rubber (Bloch et Schneider); bronze croaker, Oto- 
lithoides biauritus (Cantor); greyfin croaker, Pennahia anea (Bloch); blackspotted croaker, Protonibea diacanthus (Lacépède); tomato hind, Cephalopholis sonnerati (Valenciennes); black grouper, Mycteroperca bonaci (Poey); Javan flounder, Pseudorhombus javanicus (Bleeker); and Indian spiny turbot, Psettodes erumei (Bloch et Schneider) (Yamaguti 1935, 1941, Crisp and Klein 1973, Sakaguchi et al. 1987a, b, Sharples and Evans 1995a, b, Hesp et al. 2002, Moravec et al. 2003, Moravec and Genc 2004, Merella et al. 2004, Moravec and Justine 2005, Moravec 2006). Since morphologically more variable males had not mostly been discovered for nematodes reported as P. lateolabracis, even from its type host $L$. japonicus, researchers used less variable females for species identification. In this regard, there is a high possibility that these nematodes reported as $P$. lateolabracis are different, yet unidentified Philometra species. In this study, male and female philometrid nematodes were obtained from the type host of $P$. lateolabracis and from two other fish species previously reported as hosts of this parasite. They were morphologically examined to reveal their true taxonomical identification. Molecular comparison in the ITS2 rDNA was also conducted to strengthen and support results obtained from the morphological studies.

\section{MATERIALS AND METHODS}

Morphological studies. Philometrid nematodes were collected from ovaries of the Japanese seaperch (Lateolabrax japonicus), chicken grunt (Parapristipoma trilineatum), and red seabream (Pagrus major) caught in Tokyo Bay, East China Sea, and Seto Inland Sea, respectively. Females were collected macroscopically. For detection and collection of males, gonads were pressed between two glass plates and examined under a stereomicroscope. Collected male and female philometrids were fixed in $70 \%$ ethanol and cleared in glycerin. After clearing, philometrids were mounted on slides. For long and coiled females, only the anterior and posterior portions were mounted on slides after measuring the total body length. Measurement and observation were performed using a light microscope (LM). The general features of males, females and first-stage larvae in the uterus of a fully gravid female philometrid were drawn using a compound LM with a Nikon drawing tube attached. Females were categorized as gravid (i.e., designated larvigerous specimen), subgravid (i.e., those containing no larvae but only eggs or developing embryos), and nongravid (i.e., those without larvae or eggs). All measurements were in millimetres. New Philometra species, together with the species where male philometrids were discovered for the first time, have been deposited at the Meguro Parasitological Museum, Tokyo (M.P.M. Coll. Nos. 18858, $18860,18862)$ and the Institute of Parasitology, České Budějovice (Coll. Nos. N-888, N-889).

Measurements of some morphological structures difficult to examine under LM were carried out using scanning electron microscope (SEM). Specimens to be examined using SEM were fixed with $70 \%$ ethanol, post-fixed in $1.25-1.5 \%$ glutalaldehyde, post-fixed in $1 \%$ osmium tetroxide, and dehydrated through series of ascending ethanol concentrations. Samples were subjected to three changes of absolute butyl alcohol and freeze dried. Freeze dried samples were subsequently sputtercoated with gold and observed under a scanning electron microscope (SEM S-4000, Hitachi).

Molecular studies. The entire genome of one male and three females of the $100 \%$ ethanol-fixed philometrids from each fish species $L$. japonicus and P. major were extracted separately using a DNeasy ${ }^{\mathrm{TM}}$ Tissue Kit from Qiagen Inc. (protocol for animal tissues). Due to the unavailability of philometrids from $P$. trilineatum for DNA extraction, a molecular study on this parasite was not performed.

The forward primer NC5f (5'-GTAGGTGAACCTGCGGA AGG ATCATT-3') and the reverse primer NC2r (5'-TTT AGTTTCTTTTCCTCCGCT) designed by Zhu et al. (1998) for sequencing the ITS region of anisakid nematodes were used. The PCR assay was performed with $1 \mu 1$ sample DNA as template in a total volume of $20 \mu \mathrm{l}$ which contained $0.6 \mu \mathrm{l}$ forward and reverse primer, $14.1 \mu \mathrm{DDW}$ and $3.7 \mu 1$ Taq mix (containing $0.1 \mu 1$ TAKARA Ex Taq ${ }^{\mathrm{TM}} \mathrm{HS} ; 2 \mu 1[10 \times]$ Ex Taq Buffer; and $48 \mu 1 \mathrm{dNTP}$ mixture). After the DNA had been initially denaturized at $94^{\circ} \mathrm{C}$ for $4 \mathrm{~min}, 30$ cycles were carried out using iCycler ${ }^{\mathrm{TM}}$ (BIO-RAD). Each cycle consisted of denaturing at $94^{\circ} \mathrm{C}$ for $30 \mathrm{sec}$, annealing at $55^{\circ} \mathrm{C}$ for $30 \mathrm{sec}$ and extension at $72^{\circ} \mathrm{C}$ for $30 \mathrm{sec}$ with final extension at $72^{\circ} \mathrm{C}$ for 7 min.

Nucleotide bases were sequenced using a DNA automatic sequencer (ABI Prism ${ }^{\circledR} 310$ Genetic Analyzer, Applied Biosystems) after purification of the selected amplified DNA. The sequenced DNA of philometrids was checked for contamination by performing a BLAST search in the NCBI (http://www. ncbi.nlm.nih.gov/). The boundaries between ITS1, 5.8s, ITS2 and $28 \mathrm{~s}$ were determined manually by comparison with other reported nematodes in the NCBI. Only the sequences encompassing the ITS2 region were used for analysis. The obtained sequences were aligned with the aid of BioEdit version 7.0.4.1. The analysis of percentage similarity (i.e., gaps included) was calculated using Clustal W (Thompson et al. 1994) and BioEdit (Ibis Biosciences, Carlsbad, CA, USA). Only the data obtained in this study, which encompasses the beginning of the ITS2 and few beginning sequences of the 28 s, were deposited and made available in the GenBank under accession numbers EF 203081 and EF 203082.

\section{RESULTS}

\section{MORPHOLOGICAL STUDIES (measurements in mm)}

Philometra lateolabracis (Yamaguti, 1935) Figs. 1, 2

Male. Body length of twenty specimens collected in January 2005 ranging from 2.07 to 2.73 ; filiform body; transparent to whitish-cream body colouration when alive; maximum width at mid-portion of body 0.040 0.052; gradually tapering towards anterior portion, then gradually broadening forming a bulbous anterior extremity; cuticle smooth; rounded anterior end; cephalic end dome-shaped, with four submedian pairs of cephalic papillae forming outer ring and four single papillae present as inner ring; small rounded mouth opening, $0.0008-0.0010$ in diameter, with pair of small round 

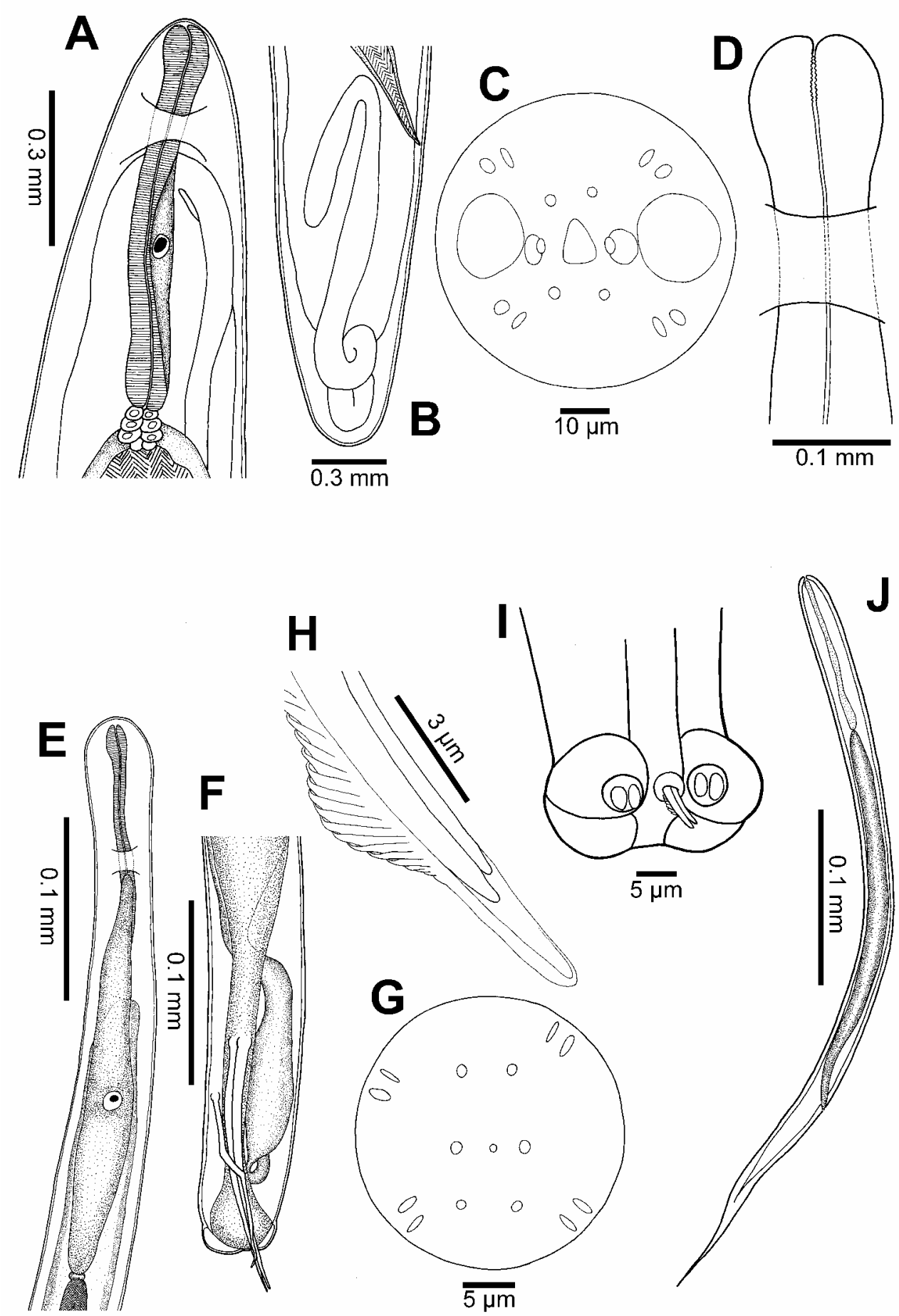

Fig. 1. Philometra lateolabracis (Yamaguti, 1935). A, B - anterior and posterior end of female; $\mathbf{C}$ - cephalic end of female, apical view; D - slightly inflated anterior end of the oesophagus in female; E, F - anterior and posterior end of male; $\mathbf{G}-$ cephalic end of male, apical view; $\mathbf{H}$ - distal ends of the spicules and gubernaculum; I - posterior end of male showing equal-sized subdivided smaller lobes, tail papillae, spicules and gubernaculum; $\mathbf{J}$ - first-stage larva.

amphids situated laterally; overall length of oesophagus 0.255-0.363, with distinct inflation (bulb formation) at its anterior end; oesophageal gland very distinct with large rounded nucleus, 0.006-0.012 in diameter, visible at its mid-portion; length of anterior part of oesophagus $0.072-0.138$, that of posterior part overlapped by oeso- phageal gland 0.12-0.25; distance of oesophageal gland nucleus and nerve ring $0.180-0.249$ and $0.030-0.116$ from anterior extremity, respectively; ventriculus present but barely visible; testis extending posteriorly up to base of spicules; spicules narrow, needle-like and unequally long; length of longer and shorter spicules 
$0.071-0.130$ and $0.065-0.124$, respectively; length ratio of spicules 1:1.03-1.12; gubernaculum narrow, 0.050 0.093 long, with proximal end part bent dorsally and with lamellate-like structures on its dorsal portion; length ratio of gubernaculum to spicules 1:1.30-2.02; posterior end of bodys rounded, with two large lobes at both sides of spicules and gubernaculum; each large lobe subdivided into two smaller equal lobes; caudal papillae observed on posterior extremity on each pair of large lobe; outlets of phasmids not observed.

Gravid female. Body length of ten specimens collected in January 2005 ranging from 112 to 206; filiform body, with slightly yellowish brown to reddish body colouration and with light to dark brown intestine when alive; maximum width at mid-portion of body 0.95-1.12; width in anterior portion of body broader, then tapering gradually to posterior portion; cuticle smooth; anterior end of body rounded; cephalic end dome-shaped with four submedian pairs of cephalic papillae arranged in outer ring and four round single papillae present as inner ring; paired cephalic papillae with slightly rounded and elongated papillae; width of small mouth opening 0.010 , triangular in shape, with a pair of amphids present on both sides; overall length of oesophagus $0.785-1.030$, broad and slightly swollen near mouth, forming slightly distinct bulb (0.065-0.105 long and 0.099-0.130 wide); narrowest width at nerve ring level, 0.068-0.110; oesophageal gland prominent, extending anteriorly to level of nerve ring and posteriorly to ventriculus, with large rounded nucleus 0.028 0.038 in diameter, located at its mid-portion; length of anterior part of oesophagus $0.212-0.230$; posterior part overlapped by oesophageal gland 0.572-0.805 long; distance of oesophageal gland nucleus and nerve ring $0.388-0.598$ and $0.170-0.295$, respectively from anterior extremity; well-developed ventriculus with length and width of $0.080-0.092$ and $0.090-0.095$, respectively; two long ovaries situated near anterior and posterior ends of body; anterior ovary sometimes reaching up to level of nerve ring, while posterior ovary nearly to body end; uterus occupying most space in body, filled with different stages of developing embryos and some first-stage larvae; posterior end of body rounded with two lateral papilla-like projections; intestine relatively narrow, with distinctly thick intestinal wall; almost black, straight and with its posterior end atrophied, forming ligament attached ventrally to body wall, far anterior to posterior extremity; vagina and vulva not observed.

Subgravid female. Body length of eight specimens collected in January 2005 ranging from 35.7 to 66.8 .

Nongravid female. Body length of ten specimens collected in January 2005 ranging from 12.65 to 16.06 .

First-stage larva. Total length and maximum width of ten first-stage larvae from uterus of gravid females collected in January 2005 ranging from 0.385 to 0.453 and from 0.015 to 0.020 , respectively; proportion of oesophageal, intestinal and tail length in relation to total body length $21-26 \%, 46-49 \%$ and $27-30 \%$, respectively.

T y p e h o s t: Lateolabrax japonicus (Cuvier) (Perciformes: Lateolabracidae); FishBase name: Japanese seaperch; Japanese name: suzuki.

Site of infection: Gonads.

P r e v a 1 e n c e : $89 \%$ (24 fish infected out of 27 fish examined).

M e a n in te n s ity: Male parasites, 153 per fish; female parasites, 10 per fish.

L o c a 1 i t y : Off Futtsu, Chiba Prefecture, Tokyo Bay, Japan $\left(35^{\circ} 45^{\prime} \mathrm{N}, 139^{\circ} 48^{\prime} \mathrm{E}\right)$.

De position of s pecimens: Meguro Parasitological Museum, Tokyo (M.P.M. Coll. No. 18862) and Institute of Parasitology, České Budějovice (Coll. No. N-252).

Comments. This species was originally reported and described by Yamaguti (1935) as Sanguinofilaria lateolabracis from fishes belonging to three different families: Lateolabrax japonicus (Lateolabracidae), Parapristipoma trilineatum (Haemulidae) and Epinephelus akaara (Serranidae). Among these three fish species, Yamaguti did not mention the type host. He only reported that Sanguinofilaria lateolabracis occur in the ovary or oviduct of various marine fishes from the $\mathrm{Pa}$ cific or the Inland Sea such as L. japonicus, P. trilineatum, E. akaara and many others. Later, Yamaguti (1941) synonymized Sanguinofilaria with Philometra and transferred this species to the latter genus. Since female $P$. lateolabracis have subsequently been reported by many authors from a wide range of host fishes, it cannot be excluded that several species may have been confused under this name (Moravec et al. 1998).

Lateolabrax japonicus, as the first host stated by Yamaguti (1935) to be infected by P. lateolabracis, can now be considered as the type host. Therefore, there was no doubt that the collected philometrids in this study, from the same host fish species, was P. lateolabracis. This was confirmed by morphological comparisons with the female $P$. lateolabracis briefly described by Yamaguti (1935). After Yamaguti's work, no other researchers have examined $P$. lateolabracis from $L$. japonicus in Japan in detail. Therefore, a full redescription of $P$. lateolabracis is provided in this paper.

Moravec and Genc (2004) reported female P. lateolabracis from different host fishes (i.e., E. marginatus and $M$. rubra) with characteristics fitting the general description of the female $P$. lateolabracis observed in this study. However, detailed morphological comparisons revealed that female $P$. lateolabracis reported by Moravec and Genc (2004) were in fact not P. lateolabracis, but rather a different species. The morphological differences of specimens reported by Moravec and Genc (2004) from E. marginatus, against those observed in the L. japonicus in this study, include the following: big rounded mouth opening (0.020-0.040 in diameter) as compared with the observed relatively small and tri- 

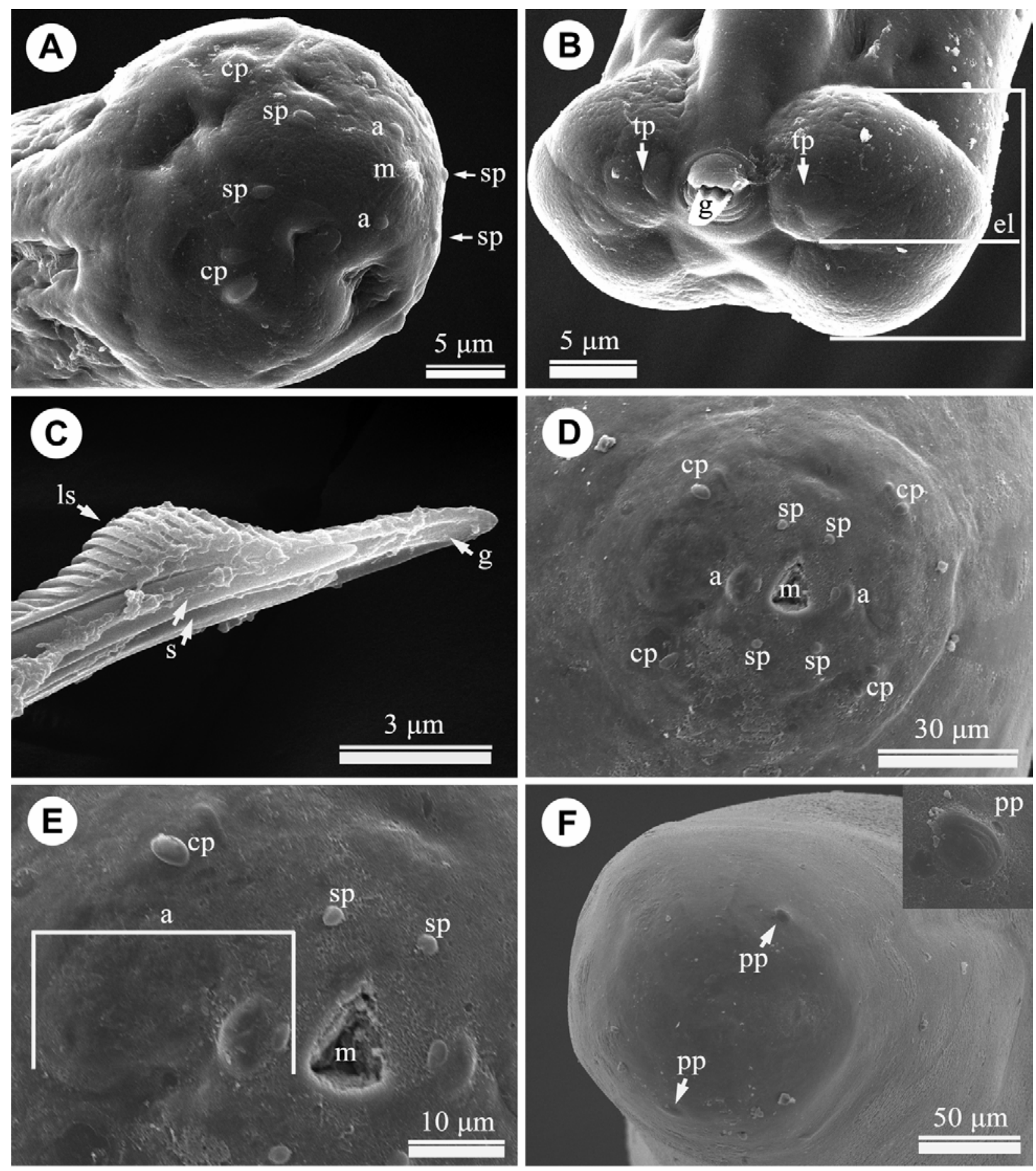

Fig. 2. Scanning electron micrographs of Philometra lateolabracis (Yamaguti, 1935). A - cephalic end of male; B - posterior end of male; $\mathbf{C}$ - distal ends of spicules and gubernaculum; note the lamellate-like structures on the gubernaculum; $\mathbf{D}$ - cephalic end of female; $\mathbf{E}$ - closer view of the amphids; F - closer view of the lateral papilla-like projections. Abbreviations: a - amphid; $\mathrm{cp}$ - paired cephalic papillae of outer circle; el - equal-sized lobes; g - gubernaculum; sp - single papilla of inner circle; ls lamellate-like structures; $\mathrm{m}$ - mouth; $\mathrm{s}$ - spicules; $\mathrm{pp}$ - lateral papilla-like projection. 
angular (0.010 maximum width) mouth opening; wider maximum body width; longer overall length of the oesophagus; bigger inflated anterior portion of the oesophagus; longer distance of the nerve ring and oesophageal gland nucleus from the anterior extremity; longer first-stage larvae inside the uterus.

Yamaguti (1935, 1961), Moravec et al. (2003), and other authors did not observe any male $P$. lateolabracis, except for Crisp and Klein (1973), Moravec and Genc (2004), and Moravec and Justine (2005), who reported that their male philometrids obtained from fish species other than $L$. japonicus were $P$. lateolabracis. Since morphologically variable and tiny males normally occur together with females, a more thorough search to actually locate these males is required. A comparison between the male $P$. lateolabracis as described by Crisp and Klein (1973) from $H$. plumieri with that observed in this study from its type host, L. japonicus, was impossible since most organs of the poorly preserved male of Crisp and Klein (1973) were not visible. The only character which was similar is the presence of unequally long spicules. On the other hand, comparison between the male $P$. lateolabracis reported by Moravec and Genc (2004) from M. rubra with the male P. lateolabracis from $L$. japonicus observed in this study revealed that these two philometrids were entirely different species; the former has longer proportion of the oesophagus in relation to the total body length, longer distance of the nerve ring and oesophageal gland nucleus to the anterior extremity and longer equal-sized spicules. Also, comparison with the male $P$. lateolabracis reported by Moravec and Justine (2005) from E. cyanopodus and E. fasciatus did not coincide with the observed morphological features of the male $P$. lateolabracis examined in this study; the former has longer body length, broad U-shaped lobular-mound at the posterior end, longer distance of the nerve ring to the anterior extremity, longer equal-sized spicules, and lacks distinct inflation at the anterior portion of the wider oesophagus.

We cannot ignore the possibility that these previously reported records of $P$. lateolabracis from other host fishes are not actually $P$. lateolabracis, but rather new and different species. This study has shown the importance of assessing males from other host fishes reported as infected with $P$. lateolabracis to clarify if these nematodes are really $P$. lateolabracis or new Philometra species. Moravec et al. (2006) reported initially that the female philometrids examined from spotted seatrout (Cyanoscion nebulosus) on the Atlantic coast of South Carolina were mostly similar to $P$. lateolabracis, but later declared it a new species ( $P$. carolinensis Moravec, de Buron et Roumillat, 2006) due to the discovery of males with differently shaped and relatively shorter spicules, and with gubernaculum possessing a dorsal barb on the distal end compared to those reported in P. lateolabracis males by Crisp and Klein (1973), Moravec and Genc (2004), and Moravec and Justine (2005). Philo- metra carolinensis females are distinctly different from $P$. lateolabracis examined in this study, particularly regarding the shape of the mouth, but the metric and meristic features in the spicules and gubernaculum are within the range of male $P$. lateolabracis.

\section{Philometra isaki sp. n.}

Figs. 3, 5

Male. Body length of eleven specimens (holotype and paratypes) collected from September 2001 to March 2003 ranging from 2.62 to 3.26 ; body filiform; transparent to whitish-cream body colouration when alive; maximum width at mid-portion of body $0.068-0.090$; broad body rapidly tapering towards anterior end, and gradually and slightly broadening forming small highly distinct bulbous inflation at anterior extremity; cuticle smooth; anterior end rounded; overall length of oesophagus $0.246-0.308$, with very small distinct inflation (bulb formation) at its anterior end; oesophageal gland very distinct with large round nucleus, $0.007-0.010$ in diameter, visible at its mid-portion; length of anterior part of oesophagus $0.081-0.168$, that of posterior part overlapped by oesophageal gland $0.107-0.220$; distance of oesophageal gland nucleus and nerve ring 0.178 0.259 and $0.100-0.157$ from anterior extremity, respectively; testis extending posteriorly up to base of spicules; spicules narrow, needle-like and unequally long; length of longer and shorter spicules 0.107-0.127 and $0.105-0.122$, respectively; length ratio of spicules 1:1.01-1.09; gubernaculum narrow, 0.07-0.09 long, with proximal part bent dorsally; length ratio of gubernaculum to spicules 1:1.33-1.74; posterior end of body rounded with two large lobes at both sides of spicules and gubernaculum; each large lobe subdivided into two smaller equal lobes; outlets of phasmids not observed.

Gravid female. Body length of ten specimens (allotype and paratypes) collected in July 2002 ranging from 167 to 420; body filiform, with yellowish-brown to reddish body colouration and with dark brown to black intestine when alive; maximum width at mid-portion of body $0.69-1.30$, anterior end of body rounded, tapering gradually to posterior portion; cuticle smooth; cephalic end dome-shaped containing four submedian pairs of cephalic papillae arranged in outer ring and four single round papillae present as inner ring; width of small mouth opening, 0.010 , somewhat triangular in shape with a pair of amphids present on both sides; overall length of oesophagus $0.79-1.10$, broad and slightly swollen near mouth forming slightly distinct bulb; narrowest width in nerve ring portion, $0.058-0.100$; bulb length, $0.058-0.115$, generally shorter than width, 0.078-0.120; oesophageal gland prominent, extending anteriorly to level of nerve ring and posteriorly to ventriculus, with large round nucleus, $0.02-0.03$ in diameter, located at its mid-portion; length of anterior part of oesophagus $0.175-0.245$, that of posterior part overlapped by oesophageal gland $0.60-0.86$; distance of 

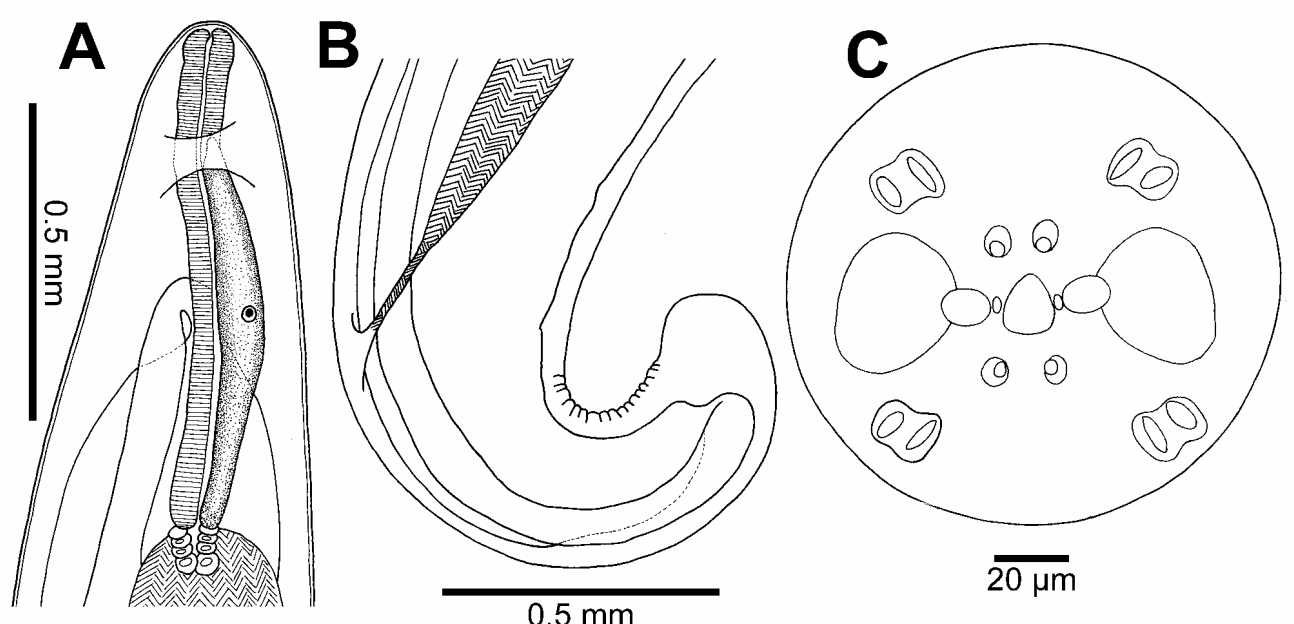

$0.5 \mathrm{~mm}$

$\mathbf{F}$
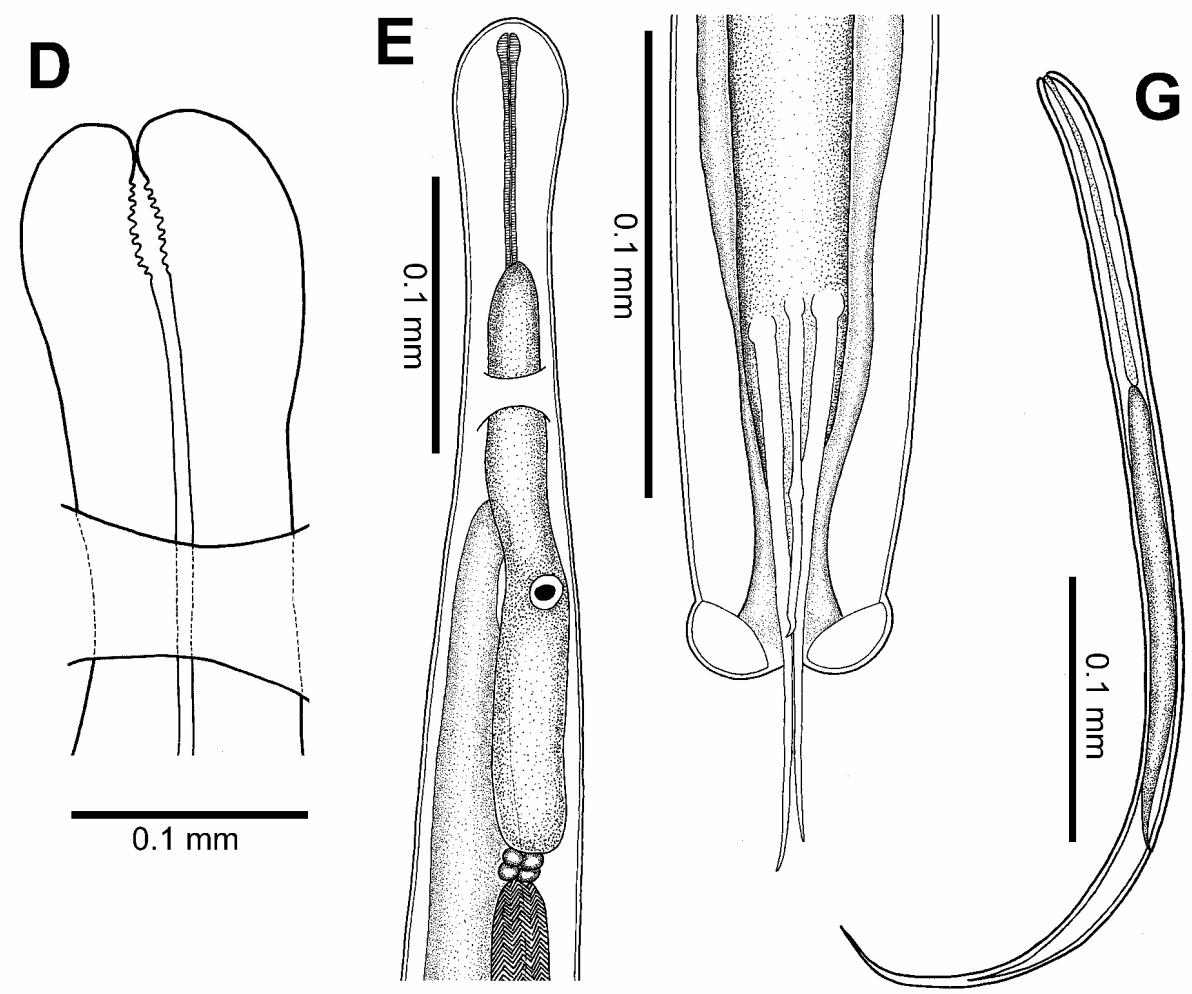

Fig. 3. Philometra isaki sp. n. A, B - anterior and posterior end of female; $\mathbf{C}$ - cephalic end of female, apical view; $\mathbf{D}$ - slightly inflated anterior end of the oesophagus in female; $\mathbf{E}, \mathbf{F}$ - anterior and posterior end of male; $\mathbf{G}$ - first-stage larva.

oesophageal gland nucleus and nerve ring $0.418-0.545$ and $0.175-0.225$ from anterior extremity, respectively; two long ovaries situated near anterior and posterior end of body; anterior ovary extending up to level of nerve ring, extending downward up to anterior portion of intestine just after ventriculus; posterior ovary reaching far posterior to intestinal ligament, sometimes almost extending to posterior end of body; uterus occupying most space in body, filled with different stages of de- veloping embryos, ready-to-hatch larvae and first-stage larvae; well-developed ventriculus with length and width of $0.075-0.095$ and $0.080-0.112$, respectively; posterior end of body rounded, with two lateral papillalike projections; intestine relatively narrow, straight and with its posterior end atrophied, forming ligament attached ventrally to body wall, $0.95-1.12$ from posterior extremity; vagina and vulva not observed. 
Subgravid female. Body length of one specimen collected in July 2002 was 131.

First-stage larva. Total length and maximum width of ten first-stage larvae from uterus of gravid females collected in July 2002 ranging from 0.355 to 0.450 and from 0.015 to 0.018 , respectively; proportion of oesophageal, intestinal and tail length in relation to total body length $27-31 \%, 37-41 \%$, and $28-36 \%$, respectively; mouth opening 0.0015 in width; two small round papillae 0.00075 in diameter, observed below the mouth; pointed boring tooth present in upper portion near mouth; cylindrical amphids protruding at both sides of mouth; width of anus, 0.002 , present in posterior portion of body besides a smaller-sized unidentified opening, 0.0005 in diameter.

$\mathrm{T}$ y p e hos t: Parapristipoma trilineatum (Thunberg) (Perciformes: Haemulidae); FishBase name: chicken grunt; Japanese name: isaki.

Site of infection: Gonads.

P r e v a 1 e n c e : 74\% (216 fish infected out of 291 fish examined).

I n t e n s i t y : Male parasites, 1-2 per fish; female parasites, 2-3 per fish

T y p e 1 o c a lity: Off Nomaike, Kagoshima Prefecture, East China Sea, Japan $\left(31^{\circ} 35^{\prime} \mathrm{N}, 130^{\circ} 08^{\prime} \mathrm{E}\right)$.

De position of specimen s: Male holotype, allotype and paratypes deposited in the Meguro Parasitological Museum, Tokyo (M.P.M. Coll. No. 18860); paratypes also in the Institute of Parasitology, České Budějovice (Coll. No. N-888).

E t y m o l o g y : This scientific name relates to the Japanese name of the fish host, i.e., isaki.

Comments. Parapristipoma trilineatum, the chicken grunt, was one of the three host fish species in which Yamaguti (1935) reported the presence of $P$. lateolabracis females. Crisp and Klein (1973) also reported the presence of a single "assumed" male and five female $P$. lateolabracis in the gonads of $H$. plumieri, a fish belonging to the same family Haemulidae. However, some morphological features used to distinguish $P$. lateolabracis from the male reported by Crisp and Klein (1973) appear doubtful wherein some differences may be due to a certain amount of intraspecific variability and some inaccuracies in observations.

Recently, Merella et al. (2004), Moravec and Genc (2004), and Moravec and Justine (2005), reported on $P$. lateolabracis males which they found in other host fishes. A morphological comparison between the observed male philometrids from $P$. trilineatum with the observed male $P$. lateolabracis from its type host $L$. japonicus in this study revealed that the philometrids from $P$. trilineatum were clearly distinguishable from $P$. lateolabracis; the former have longer body length, broader body width, shorter proportion of oesophageal length in relation to total body length, longer distance of nerve ring to anterior extremity and longer unequalsized spicules. The discovery of male $P$. lateolabracis in this study will serve as a basis in the re-identification of
P. lateolabracis reported from fishes other than L. japonicus.

The female $P$. isaki from $P$. trilineatum was compared with the $P$. lateolabracis reported by Yamaguti (1935), and with the fully described female of the type species $P$. lateolabracis from $L$. japonicus observed in this study. Generally, similar morphological features were observed except for the nearly double maximum length of gravid females and relatively lower oesophageal length ratio in relation to the total body length in $P$. isaki. With these morphological differences observed, it is necessary to classify $P$. isaki from its type host fish $P$. trilineatum as a new species.

Additionally, some morphological differences were also observed in the first-stage larvae found inside the uterus of gravid females. These differences between the hatched larvae of $P$. lateolabracis and those of $P$. isaki include a shorter proportion of oesophageal length and longer proportion of intestinal length in relation to total body length in P. lateolabracis.

Philometra madai sp. n.

Figs. 4, 5

Male. Body length of eight specimens (holotype and paratypes) collected from September 2004 to October 2005 ranging from 3.92 to 5.94; filiform body; transparent to whitish-cream body colouration when alive; length 3.92-5.94; maximum width at mid-portion of body $0.096-0.132$; gradually tapering towards anterior end without formation of bulbous anterior extremity; cuticle smooth; rounded anterior end; cephalic end dome-shaped with four submedian pairs of cephalic papillae arranged in outer ring and four single papillae present as inner ring; small round mouth, 0.003 in diameter, with a pair of amphids on its opposite sides; overall length of oesophagus $0.43-0.49$, with inflation (bulb formation) at anterior end; oesophageal gland very distinct, with large round nucleus, 0.007 in diameter, at its mid-portion; length of anterior part of oesophagus $0.12-0.14$, that of posterior part overlapped by oesophageal gland 0.31-0.35; distance of oesophageal gland nucleus and nerve ring $0.317-0.354$ and $0.04-0.08$ from anterior extremity, respectively; length and width of ventriculus $0.028-0.032$ and 0.025 , respectively; testis very broad occupying most spaces within body during its spawning season from June to July 2005, extending posteriorly up to base of spicules; spicules narrow, needle-like and slightly unequally long; length of longer and shorter spicules $0.084-0.100$ and $0.077-0.100$, respectively; length ratio of spicules 1:1.00-1.16; gubernaculum narrow, 0.064-0.084 long, with proximal tip bent and with lamellate-like structures on its dorsal portion; length ratio of gubernaculum to spicules 1:1.011.40; posterior end of body rounded, with two large lobes at both sides of spicules and gubernaculum; each posterior lobe subdivided into two smaller unequal lobes, 0.012 and 0.005 in length; two tail papillae observed in posterior extremity in smaller-sized subdivided lobe; outlets of phasmids not observed. 

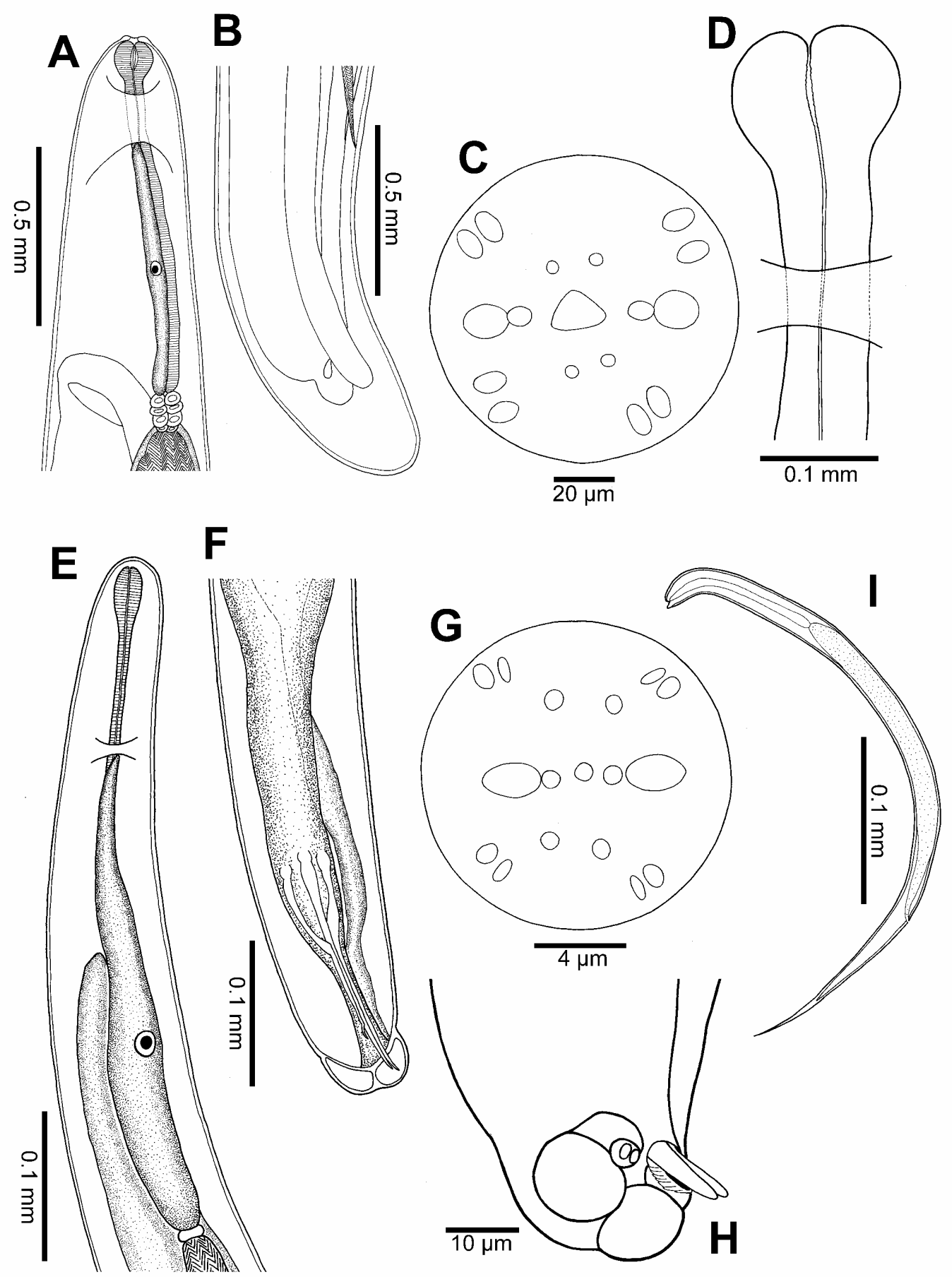

Fig. 4. Philometra madai sp. n. A, B - anterior and posterior end of female; C - cephalic end of female, apical view; D - highly inflated anterior end of the oesophagus in female; $\mathbf{E}, \mathbf{F}$ - anterior and posterior end of male; $\mathbf{G}$ - cephalic end of male, apical view; $\mathbf{H}$ - closer view of posterior end of male showing the unequal-sized subdivided smaller lobes, tail papillae, spicules and gubernaculum; I - first-stage larva.

Gravid female. Body length of four specimens (allotype and paratypes) collected from May to July 2005 ranging from 103.8 to 394.4 ; filiform body with yellowish brown to reddish body colouration and with light- to dark brown intestine when alive; maximum width at mid-portion of body $0.62-1.60$; body at anterior portion broader, tapering gradually to posterior portion; cuticle smooth; anterior end of body rounded; cephalic end dome-shaped containing four submedian pairs of cephalic papillae as outer ring and four single papillae as inner ring; wide rounded mouth opening, 0.025 in diameter, with pair of amphids on its opposite sides; over- 

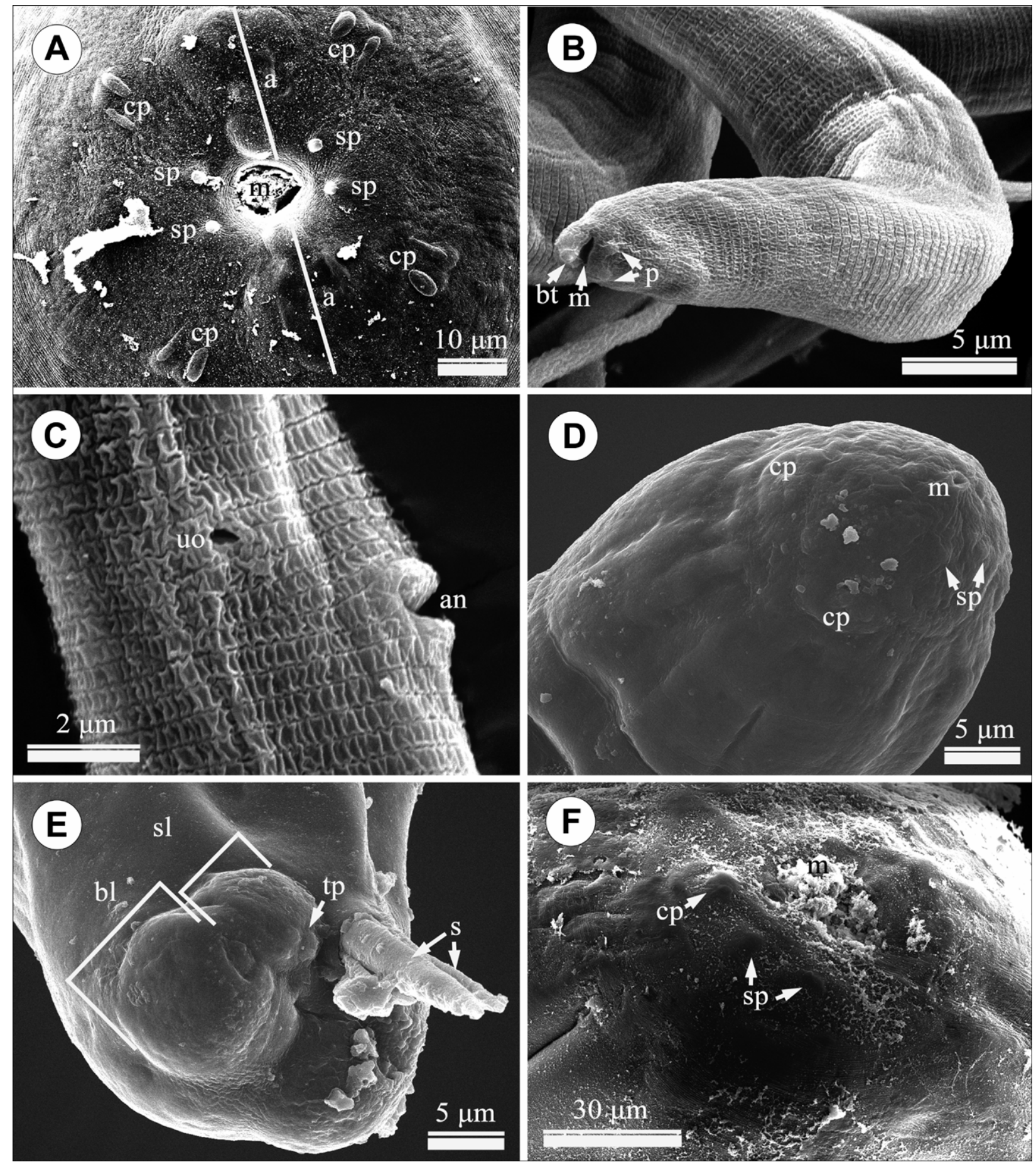

Fig. 5. Scanning electron micrographs of Philometra isaki sp. n. (A-C) and Philometra madai sp. n. (D-F). A - cephalic end of female, apical view; $\mathbf{B}$ - anterior end of first-stage larva showing the boring tooth, papillae and amphids near the mouth opening; $\mathbf{C}$ - posterior end of first-stage larva showing the bigger-sized anus besides an unidentified smaller-sized opening; $\mathbf{D}$ - cephalic end of male, sub-apical view; $\mathbf{E}$ - posterior end of male showing the unequal-sized subdivided smaller lobes; $\mathbf{F}$ - cephalic end of female. Abbreviations: a - amphid; an - anus; bl - bigger-sized lobe; bt - boring tooth; $\mathrm{cp}$ - paired cephalic papillae of outer circle; $g$ - gubernaculum; $s p$ - single papillae of inner circle; $\mathrm{m}$ - mouth; $\mathrm{p}$ - papillae; $\mathrm{sl}$ - smaller-sized lobe; $\mathrm{s}$ - spicules; tp tail papillae; uo - unidentified opening. 
all length of relatively narrow oesophagus $1.06-1.12$; its anterior portion highly swollen forming distinct bulb; narrowest width in nerve ring portion, 0.050-0.115; bulb length, 0.090-0.102, generally shorter than width (0.110-0.158); oesophageal gland prominent, extending anteriorly to level of nerve ring and posteriorly to ventriculus, with large round nucleus, 0.032 in diameter, located at its mid-portion; length of anterior part of oesophagus $0.265-0.312$, that of posterior part overlapped by oesophageal gland $0.748-0.835$; distance of oesophageal gland nucleus and nerve ring $0.67-0.71$ and 0.24-0.34 from anterior extremity, respectively; welldeveloped ventriculus with length and width of 0.095 0.140 and $0.078-0.100$, respectively; with two long and broad ovaries, situated near anterior and posterior end of body; anterior ovary usually starting at about mid-length of oesophagus, extending downward up to anterior portion of intestine just after ventriculus; posterior ovary reaching far posterior to intestinal ligament, sometimes almost extending to posterior end of body; uterus very broad, occupying most space in body, filled with different stages of developing embryos and first-stage larvae; posterior end of body rounded; lateral papilla-like projections not observed; intestine relatively narrow with moderately thick intestinal wall, straight and with posterior end atrophied, forming ligament attached ventrally to body wall; vagina and vulva not observed.

Subgravid female. Body length of three specimens collected in June 2005 ranging from 31.66 to 39.0.

Nongravid female. Body length of a single specimen collected in June 2005 was 20.47.

First-stage larva. Total length and maximum width of ten first-stage larvae from uterus of gravid females collected in July 2005 ranging from 0.450 to 0.522 and from 0.012 to 0.018 , respectively; proportion of oesophageal, intestinal and tail length in relation to total body length was $28-34 \%, 36-43 \%$ and $25-31 \%$, respectively.

Ty p e hos t: Pagrus major (Temminck et Schlegel) (Perciformes: Sparidae); FishBase name: red seabream; Japanese name: madai.

Site of infection: Gonads.

P r e va l e n c e : $11 \%$ (75 fish infected out of 650 fish examined).

I n t e n s i t y : Male parasites, 1 per fish; female parasites, 12 per fish.

Ty p e 1 o c a 1 it y : Off Shimonada, Ehime Prefecture, Seto Inland Sea, Japan (334ㄴ $\left.\mathrm{N}, 132^{\circ} 36^{\prime} \mathrm{E}\right)$.

De p os ition of s pe ci m e n s: Male holotype, allotype and paratypes deposited in the Meguro Parasitological Museum, Tokyo (M.P.M. Coll. No. 18858); paratypes also in the Institute of Parasitology, České Budějovice (N-889).

E t y m o 1 o g y : This scientific name relates to the Japanese name of the fish host, i.e., madai.

Comments. Yamaguti (1961) found and identified for the first time single, not fully mature female nematodes in the swim bladder of the black porgy [Acantho- pagrus schlegeli (Bleeker)] as Philometra spari. The nematode found by Sakaguchi and Matsusato (1978) in the body cavity of $P$. major caught in Kariya Bay, Saga Prefecture was also identified as $P$. spari due to the morphological similarities observed. Nakajima and Egusa (1979) examined cultured $P$. major from the coast of Amami Island, Kagoshima prefecture, and found philometrid nematodes in its gonads. They reported it as an unknown species (Philometra sp.), and not $P$. spari because of the difference in habitat of the worm in the host and the location of the uterus in the gravid female worm. Sakaguchi et al. (1987a, b) reidentified the philometrid nematodes obtained from red seabream as $P$. lateolabracis, which was previously reported as $P$. spari. Sharples and Evans (1995a, b) also reported the presence of female $P$. lateolabracis in New Zealand from snapper Pagrus auratus, a host fish belonging to the same genus (Pagrus Cuvier). Sakaguchi et al. (1987b) and Sharples and Evans (1995a, b) did not describe morphological characteristics of their nematodes in detail. Their morphological examinations, being closest to $P$. lateolabracis, which was always reported to infect diverse marine fishes, might have made them identify their specimens as $P$. lateolabracis. Since all of these researchers were not successful in finding the morphologically more variable males, it was not clear if these nematodes were P. spari, P. lateolabracis, or other Philometra species.

The majority of morphological structures of the $P$. lateolabracis females described in this study have some similarities with $P$. madai. However, there were several features that differentiate $P$. madai from $P$. lateolabracis. The major difference observed in the $P$. madai female is the highly inflated anterior portion of the narrow oesophagus, which is distinctly different from that of the female $P$. lateolabracis (i.e., slightly inflated and wide oesophagus). In males, the major differences observed in $P$. madai, compared to P. lateolabracis, include the total body length (nearly two times longer), narrower body, presence of paired large posterior lobes on both sides of the spicule and gubernaculum which are subdivided into two unequal-sized smaller lobes, and a different length ratio of spicules and gubernaculum. In this regard, the previously reported P. lateolabracis from $P$. major was a misidentification. Hence, with these various morphological differences observed, it is therefore necessary to suggest $P$. madai as a new species.

\section{MOLECULAR STUDIES}

Philometra madai (429 bases) had a higher number of nucleotide bases in the ITS2 rDNA than P. lateolabracis (418 bases). The percentage similarity of sequences (gaps included) between the two species was $70 \%$ while intraspecific similarities were above $99.7 \%$ in both species (Table 1). These molecular data support the finding that $P$. lateolabracis and P. madai are dif- 
Table 1. Identity matrix of ITS2 sequences between four individual specimens of Philometra lateolabracis (Yamaguti, 1935) and Philometra madai sp. n. (gaps included).

\begin{tabular}{lccccccccccc}
\hline \multicolumn{1}{c}{ Species } & $\begin{array}{l}\text { Individual } \\
\text { specimens }\end{array}$ & No. bp & A & B & C & D & E & F & G & H \\
\hline $\begin{array}{l}\text { P. lateolabracis } \\
\text { (from }\end{array}$ & A & 418 & - & 1 & 1 & 1 & 0.697 & 0.697 & 0.7 & 0.7 \\
Lateolabrax japonicus) & $\mathrm{B}$ & 418 & 1 & - & 1 & 1 & 0.697 & 0.697 & 0.7 & 0.7 \\
& $\mathrm{C}$ & 418 & 1 & 1 & - & 1 & 0.697 & 0.697 & 0.7 & 0.7 \\
& $\mathrm{D}$ & 418 & 1 & 1 & 1 & - & 0.697 & 0.697 & 0.7 & 0.7 \\
\hline $\begin{array}{l}\text { P. madai } \\
\text { from Pagrus major) }\end{array}$ & $\mathrm{E}$ & 429 & 0.697 & 0.697 & 0.697 & 0.697 & - & 1 & 0.997 & 0.997 \\
& $\mathrm{~F}$ & 429 & 0.697 & 0.697 & 0.697 & 0.697 & 1 & - & 0.997 & 0.997 \\
& $\mathrm{G}$ & 429 & 0.7 & 0.7 & 0.7 & 0.7 & 0.997 & 0.997 & - & 1 \\
& $\mathrm{H}$ & 429 & 0.7 & 0.7 & 0.7 & 0.7 & 0.997 & 0.997 & 1 & - \\
\hline
\end{tabular}

A - male P. lateolabracis; B - female P. lateolabracis No. 1; C - female P. lateolabracis No. 2; D - female P. lateolabracis No. 3; E - male P. madai; $\mathrm{F}$ - female P. madai No. 1; G - female P. madai No. 2; $\mathrm{H}$ - female P. madai No. 3.

Table 2. Identity matrix of ITS2 sequences between currently studied Philometra species and other sequences of Philometra in GenBank (gaps included).

\begin{tabular}{|c|c|c|c|c|c|c|c|c|c|c|}
\hline Species & Host & Location & No. bp & P. lat & P. mad & $P . f u j$ & P. cla & $P . \mathrm{sp}$. & $\begin{array}{l}\text { GenBank } \\
\text { Acc. No. }\end{array}$ & Author \\
\hline P. lateolabracis & $\begin{array}{l}\text { Lateolabrax } \\
\text { japonicus }\end{array}$ & $\begin{array}{l}\text { Tokyo Bay, } \\
\text { Japan }\end{array}$ & 418 & - & & & & & EF203081 & present study \\
\hline P. madai & Pagrus major & $\begin{array}{l}\text { Seto Inland } \\
\text { Sea, Japan }\end{array}$ & 429 & 0.697 & - & & & & EF203082 & present study \\
\hline $\begin{array}{l}\text { P. fujimotoi } \\
\text { (Furuyama, 1932) }\end{array}$ & $\begin{array}{l}\text { Channa argus } \\
\text { (Cantor) }\end{array}$ & $\begin{array}{l}\text { Upper Yangtze } \\
\text { River, China }\end{array}$ & 517 & 0.348 & 0.355 & - & & & DQ076690 & $\begin{array}{l}\text { Wu et al. } 2005 \\
\text { (unpublished) }\end{array}$ \\
\hline $\begin{array}{l}\text { P. clavaeceps } \\
\text { Dogiel et Akhmerov, } \\
1959\end{array}$ & $\begin{array}{l}\text { Culter } \\
\text { erythropterus } \\
\text { Basilewsky }\end{array}$ & $\begin{array}{l}\text { Liangzi Lake, } \\
\text { Hubei, China }\end{array}$ & 505 & 0.418 & 0.437 & 0.343 & - & & DQ076696 & $\begin{array}{l}\text { Wu et al. } 2005^{*} \\
\text { (unpublished) }\end{array}$ \\
\hline Philometra sp. & $\begin{array}{l}\text { Siniperca chuatsi } \\
\text { Basilewsky }\end{array}$ & China & 731 & 0.243 & 0.236 & 0.279 & 0.212 & - & EF127904 & $\begin{array}{l}\text { Wu and Wang } 2006 \\
\text { (unpublished) }\end{array}$ \\
\hline
\end{tabular}

*The reported host (Cultrichthys erythropterus) is a synonym of Culter erythropterus.

ferent species, which is in contrast to the previous reports that philometrids from P. major were P. lateolabracis. Even though $P$. isaki was not sequenced due to unavailable samples, its description as a new species could still be strongly supported by the morphological data obtained. Further molecular comparison with the ITS2 sequences reported under Philometra in the GenBank showed that the Philometra species examined in this study were obviously different (Table 2). The similarity of $70 \%$ between $P$. lateolabracis and P. madai is in contrast to the interspecific similarity of $21.2-43.7 \%$ among previously studied species. This suggests a close phylogenetic relationship between $P$. lateolabracis and $P$. madai compared to previously studied species.

\section{DISCUSSION}

In conclusion, the discovery of male $P$. lateolabracis from its type host, $L$. japonicus, clarified the taxonomical identification of the previously reported P. lateolabracis observed in $P$. trilineatum and $P$. major. This study showed the importance of searching for male philometrids from other reported $P$. lateolabracisinfected hosts. Such results would confirm if these philometrids are indeed P. lateolabracis or new Philometra species. The use of molecular studies, especially of the highly variable ITS regions, can be a useful tool in supporting morphological data from further taxonomic studies. Since most Philometra species were identified only using female parasites, the effort in assessing males and using molecular studies are required for proper and precise identification to species level.

Acknowledgements. We wish to thank the Ministry of Education, Culture, Sports, Science and Technology, Government of Japan (MEXT) for financially supporting this research. Thanks are also due to Y. Matsumaru, M. Chiba, and S. Atsuchi of the Chiba Prefectural Fisheries Research Center, Ehime Prefectural Chu-yo Fisheries Experimental Station, and Kagoshima Prefectural Fisheries Experimental Station, respectively, for the samples provided. We also thank Mudjekeewis D. Santos of the Laboratory of Genome Science, Tokyo University of Marine Science and Technology for the molecular analysis and improving the contents of this paper. 


\section{REFERENCES}

CRISP D.J., KLEIN V.L.M. 1973: Contribution to the knowledge of Philometra lateolabracis Yamaguti, 1935 (Nematoda: Filaroidea). Mem. Inst. Oswaldo Cruz 71: 481-483.

HeSP S.A., HobBS R.P., POTTER I.C. 2002: Infection of the gonads of Glaucosoma hebraicum by the nematode Philometra lateolabracis: occurrence and host response. J. Fish Biol. 60: 663-673.

Merella P., ReÑones O., GARIPPA G. 2004: Finding of one male Philometra lateolabracis (Nematoda: Philometridae) parasite on the dusky grouper Epinephelus marginatus (Osteichthyes: Serranidae) in the western Mediterranean. Parassitologia 46 (Suppl. 1): 158.

MORAVEC F. 2004: Some aspects of the taxonomy and biology of dracunculoid nematodes parasitic in fishes: a review. Folia Parasitol. 51: 1-13.

MORAVEC F. 2006: Dracunculoid and Anguillicoloid Nematodes Parasitic in Vertebrates. Academia, Praha, $634 \mathrm{pp}$.

MORAVEC F., DE BURON I., ROUMILlAT W.A. 2006: Two species of Philometra (Nematoda: Philometridae) parasitic in the perciform fish Cynoscion nebulosus (Sciaenidae) in the estuaries of South Carolina, USA. Folia Parasitol. 53: 63-70.

MORAVEC F., GENC E. 2004: Redescription of three Philometra spp. (Nematoda, Philometridae) from the gonads of marine perciform fishes of Iskenderun Bay (North-East Mediterranean), Turkey. Acta Parasitol. 49: 31-40.

Moravec F., Glamuzina B., Marino G., Merella P., Cave D.D. 2003: Occurrence of Philometra lateolabracis (Nematoda: Philometridae) in the gonads of marine perciform fishes in the Mediterranean region. Dis. Aquat. Org. 53: 267-269.

Moravec F., Justine J. 2005: Two species of Philometra (Nematoda, Philometridae) from serranid fishes off New Caledonia. Acta Parasitol. 50: 323-331.

MORAVEC F., NAGASAWA K., OGAWA K. 1998: Observations on five species of philometrid nematodes from marine fishes in Japan. Syst. Parasitol. 40: 67-80.
NAKAJIMA K., EGUSA S. 1979: Philometra sp. found on the gonads of cultured red sea bream. Fish Pathol. 13: 197-200. (In Japanese, Engl. summary.)

SAKAGUCHI S., MATSUSATO T. 1978: On a nematode, Philometra found in a red sea bream, Chrysophrys major - I. Bull. Nansei Reg. Fish. Res. Lab. 11: 27-32. (In Japanese, Engl. summary.)

SAKAGUChI S., Shibahara T., YAMAGATA Y. 1987a: Parasitic ecology of a Philometra lateolabracis parasite on the red sea bream. Bull. Nat. Res. Inst. Aquacult. 12: 73-78. (In Japanese, Engl. summary.)

SAKAGUCHI S., YAMAGATA Y., SAKO H. 1987b: Reidentification of Philometra parasitic on the red sea bream. Bull. Nat. Res. Inst. Aquacult. 12: 69-72. (In Japanese, Engl. summary.)

SHARPLES A.D., Evans C.W. 1995a: Metazoan parasites of the snapper, Pagrus auratus (Bloch \& Schneider, 1801) in New Zealand. 1. Prevalence and abundance. N.Z. J. Marine Freshwater Res. 29: 195-201.

ShaRPLeS A.D., Evans C.W. 1995b: Taxonomy of the metazoan parasites of the snapper Pagrus auratus in New Zealand. 2. Endoparasites. N.Z. J. Zool. 22: 163-174.

THOMPSON J.D., HIGGINS D.G., GIBSON T.J. 1994: Clustal_W: Improving the sensitivity of progressive multiple sequence alignment through sequence weighting, position-specific gap penalties and weight matrix choice. Nucleic Acids Res. 22: 4673-4680.

YAMAGUTI S. 1935: Studies on the helminth fauna of Japan. Part 9. 1. Nematodes of fishes, I. Jpn. J. Zool. 6: 337-386.

YAMAGUTI S. 1941: Studies on the helminth fauna of Japan. Part 33. Nematodes of fishes,II. Jpn. J. Zool. 9: 343-396.

YAMAGUTI S. 1961: Studies on the helminth fauna of Japan. Part 57. Nematodes of fishes, III. J. Helminthol., R.T. Leiper Suppl., 217-228.

ZHU X., Gasser R.B., Podolska M., ChILTON N.B. 1998: Characterization of anisakid nematodes with zoonotic potential by nuclear ribosomal DNA sequences. Int. J. Parasitol. 28: 19111921.

Accepted 19 November 2007 